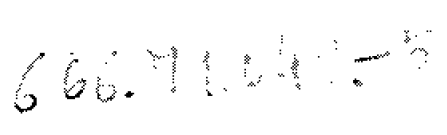

Se ha construido un dispositivo, para ser utilizado en el secadero, con el cual se ha podido supervisar el proceso del secado. Como puede verse en la figura consto de las siguientes portes:

Una plataforma, 4, en la cual se colocon, por ejemplo, dos ladrillos crudos que se van a secar, y va suspendida, en un lugar adecuado del secadero, por medio dé unos ganchos; 3 , que atraviesan el techo de la cámara; éstos, a su vez, van enganchados en unos levas que giran alrededor del eje, 1 . Este eje va dispuesto de tal forma que puede girar libremente y va montado sobre la cómora de secado. Al otro extremo del eje, $1, y$ fuera del secadero, hoy otra leva, 5 , de la que cuelgan el recipiente, $6, y$ un contrapeso, 8 . El recipiente, 6 , tiene una válvula de aguja, 7. Todo este sistema sirve para equilibrar al conjunto, 2, 3, 4, y a los ladrillos húmedos. El recipiente, 6 , ha de estar parcialmente lleno de agua hasto, aproximadamente, un $20 \%$ de su volumen.

Si antes de empezar el secado se vierte agua on el recipiente, 6, éste descenderó; entonces la aguja, 7 , que permanece fija por estor sujetc en el soporte, 9, deja abierto el agujero que hay en el fondo del recipiente y descarga cierta cantidad de agua, hasta que $5 \theta$ restablece el equilibrio, entre los dos sistemas, en cuyo momento el recipiente sube y cierra el orificio la aguja.

Debajo del recipiente, 6 , se coloca una probeta graduada, 10 . Durante el secado los ladrillos pierden ogua, $y$ por tanto peso, y al desequilibrarse el sistema se abrirá la válvula de aguja y goteará una cierta cantidad de ogua, hasta que se recupere el equilibrio y se cierre nuevamente el orificio. La cantidad de agua que cae es, precisamente, la que se evapora de los ladrillos durante el secado.

La leva, 5, puede tener doble longitud que las levas, 2, y, por tanto, los elementos, $6,8,10$, pueden ser más pequeños.

Dependiendo de las condiciones existentes puede disponerse un sistema de po-

\section{control continuo del secado}

ERICH IUTHER

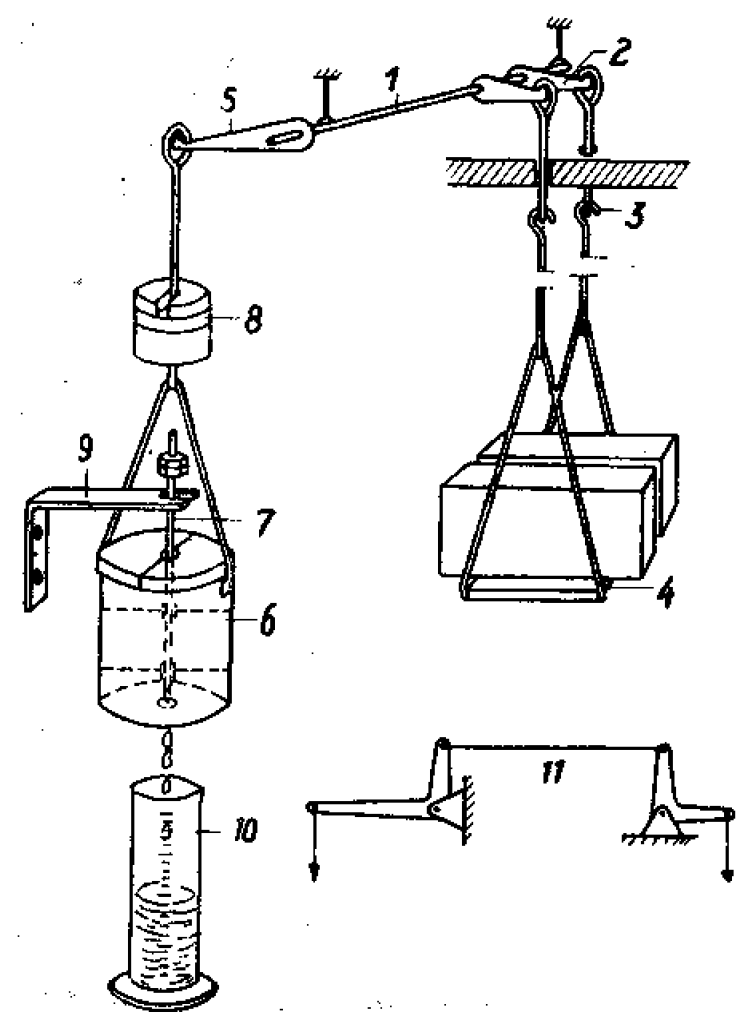

lancas como el que se indica en 11, el cual sustituye al sistema, $1,3,5$.

Según la revista «Ziegelindustrie», el diámetro más adecuado que se le puede dar al orificio de la válvula de aguja es de unos dos milímetros.

(Aparentemente se trata de un dispositivo muy ingenioso, ounque complicado. Otro procedimiento más sencillo consiste en colocar un ladrillo sobre el platillo de un peso de dinamómetro de resorte y fijarlo sobre una vagonefa de secadero. Puede saberse la morcha del secado por la pérdida de peso aunque, naturalmente, es necesario entrar en ía cámara para efectuar las fecturas, mientras que por el procedimiento descrito puede leerse desde el exteriorl.

C. S. C. 